\title{
DESAIN DAN REALISASI ACCELEROMETER BERBASIS ARDUINO SEBAGAI INSTRUMEN PENDETEKSI MIKROTREMOR
}

\author{
Ahmad Amiruddin', Suharno ${ }^{2}$, Karyanto $^{3}$ \\ 1,2,3 Jurusan Teknik Geofisika, Fakultas Teknik Universitas Lampung \\ Corresponding author: ahmadamir2626@gmail.com \\ Manuscript received: June 11, 2019, revised :30 June, 2019; \\ Approved: September 17, 2019; available online: November 11, 2019
}

\begin{abstract}
Abstrak - Untuk melakukan investigasi zona kerawanan tanah salah satunya dengan analisa mikrotremor untuk menganalisa karakteristik tanah berdasarkan frekuensi alami lapisan tanah. Namun, teknologi yang digunakan untuk mendapatkan data tersebut masih mahal dan belum bisa digunakan banyak orang. Mengingat kebutuhan teknologi ini, maka penelitian ini dilakukan untuk merancang alat untuk analisis mikrotremor berupa accelerometer berbasis Arduino yang terjangkau biaya dan lebih mudah digunakan. Penelitian ini bertujuan membuat rancang bangun accelerometer, membuat sistem dan program accelerometer dan melakukan validasi hasil pengukuran. Hasilnya, rancang bangun tubuh alat berbentuk box dengan ukuran $18,5 \mathrm{~cm}$ x $12 \mathrm{~cm}$ x $7 \mathrm{~cm}$ dengan alas box terbuat dari plat besi sebagai medium getaran dan tutup box terbuat dari mika. Perancangan program mulai dari akuisisi, hingga penyimpanan data dengan sampling rate maksimal 500/s. Seluruh komponen dan program dan diuji agar bekerja secara efisien dan optimal. Hasil uji validasi dari masing-masing titik dari alat uji menghasilkan nilai $f_{0}$ dari kurva $H V S R$ berkisar antara $0,19 \mathrm{~Hz}-0,93 \mathrm{~Hz}$. Sedangkan dari alat Reftek Accelerograph menghasilkan nilai kisaran $0,18 \mathrm{~Hz}-0,90 \mathrm{~Hz}$. Selisih terkecil antara kedua alat pengukuran yaitu $0,007 \mathrm{~Hz}$ di titik 1 dan selisih terbesar yaitu $0,12 \mathrm{~Hz}$ di titik 3 . Rata rata selisih kedua nilai $f_{0}$ pengukuran yaitu $0,03 \mathrm{~Hz}$.
\end{abstract}

\begin{abstract}
To investigate soil vulnerability zones, one of the methods is microtremor analysis to analyze soil characteristics based on the natural frequency of the soil layer. However, the technology used to obtain the data is still expensive. Considering the need for this technology, this research was conducted to design a tool used as a microtremor analysis with Arduino-based accelerometer which is affordable and easier to use. As a result, the design of the accelerometer body size is $18.5 \mathrm{~cm} \times 12 \mathrm{~cm} \times 7 \mathrm{~cm}$ with the bottom side of the box made of the iron plate as a vibration medium and the lid box is made of mica. The program system can work efficiently with a maximum sampling rate of data collection of 500/s. From the validation test, the $f_{0}$ value of the HVSR curve from the accelerometer tool ranges from $0.19 \mathrm{~Hz}-0.93 \mathrm{~Hz}$. Whereas from the reference tool Reftek Accelerograph produces a range of $0.18 \mathrm{~Hz}-0.90 \mathrm{~Hz}$. The smallest difference between the two measurement tools is $0.0072 \mathrm{~Hz}$ at point 1 and the biggest difference is $0.1299 \mathrm{~Hz}$ at point 3 . The average difference between the two values of f0 is $0.0377 \mathrm{~Hz}$.
\end{abstract}

Keyword : Microtremor, Arduino, Accelerometer, Instrument

How to cite this article:

Amiruddin, A., Suharno dan Karyanto, 2019, Desain dan Realisasi Accelerometer Berbasis Arduino Sebagai Instrumen Pendeteksi Mikrotremor, Jurnal Geofisika Eksplorasi, 5 (3) p.162-173. doi: 10.23960/ jge.v5i3.31

\section{PENDAHULUAN}

Salah satu upaya mitigasi bencana gempa bumi dan pergerakan tanah adalah melakukan analisis kerawanan tanah pada daerah yang diindikasi memiliki potensi bencana atau kerentanan tinggi. Untuk melakukan investigasi zona kerawanan tanah salah satunya dengan analisa mikrotremor. Mikrotremor adalah metoda geofisika yang digunakan untuk menganalisa karakteristik tanah berdasarkan kecepatan gelombang seismik dengan menganalisis variasi amplitudo periode dan frekuensi terhadap waktu yang disebabkan oleh gempa bumi maupun 
sumber getaran yang lain. Hasil dari mikrotremor berupa klasifikasi tanah dan perhitungan faktor amplikasi lapisan sedimen permukaan.

Namun, teknologi yang digunakan untuk mendapatkan data tersebut masih mahal dan belum bisa digunakan banyak orang. Mengingat kebutuhan akan teknologi ini, maka perlu dilakukan penelitian untuk merancang alat yang digunakan sebagai analisis mikrotremor berupa accelerometer berbasis Arduino yang lebih terjangkau biaya dan lebih mudah digunakan.

Beberapa penelitian sebelumnya yang telah menggunakan Arduino sebagai microcontroller seperti yang dilakukan oleh Ardhi (2018) mengenai alat pendeteksi gempa menggunakan Arduino dengan sensor accelerometer dan menghasilkan suatu sistem pendeteksi gempa sederhana yang lebih mudah dirancang dan digunakan. Selain itu, pada penelitian oleh Purwowibowo (2017) yaitu melakukan desain accelerometer menggunakan Arduino untuk aplikasi pada identifikasi getaran mesin sebagai identifikasi kerusakannya dan mengetahui stabilitas accelerometer yang digunakan.

Dari penelitian tersebut, maka penelitian mengenai perancangan accelerometer berbasis Arduino sebagai instrumen identifikasi mikrotremor dapat memiliki manfaat sebagai identifikasi nilai kerentanan suatu wilayah yang teknologinya relatif lebih murah dan dapat dilakukan pengembangan lebih lanjut.

\section{TINJAUAN PUSTAKA}

\subsection{Arduino Mega2560}

Arduino adalah suatu papan elektronik berbasis microcontroller yang berisi suatu rangkaian elektronik memiliki suatu chip IC (integrated circuit) yang dapat diprogram dengan komputer melalui Arduino IDE dan memiliki sifat open source. Tujuan perangkaian elektronik pada Arduino ini adalah untuk membaca input, melakukan proses dan menghasilkan proses sesuai dengan input program yang telah dimasukkan ke dalam microcontroller berdasarkan proses dalam rangkaian elektronik. Papan Arduino Mega ditunjukkan pada Gambar 1. (www.theengineer ingprojects.com).

\subsection{Sensor ADXL345}

ADXL345 adalah salah satu sensor yang dapat merespon percepatan berdasarkan getaran maupun kemiringan. ADXL345 memiliki sensor 3 sumbu dan memiliki resolusi 13 bit dengan jangkauan $2 \mathrm{~g}, 4 \mathrm{~g}, 8 \mathrm{~g}$ dan 16g. Sensor ADXL345 ditunjukkan pada Gambar 2 (www.sparkfun.com).

\subsection{Perancangan Sistem Pendeteksi Gempa}

Pada penelitian yang dilakukan oleh Ardhi (2018) yang bertujuan untuk merancang sistem pendeteksi gempa berbasis Arduino dan sensor accelerometer. Studi ini dilakukan untuk melihat kegunaan Arduino dan sensor accelerometer untuk diaplikasikan pada sistem pendeteksi gempa. Sistem ini terdiri dari microcontroller Arduino Uno, sensor accelerometer dan sensor getar. Microcontroller Arduino Uno digunakan sebagai pengolah data yang di deteksi oleh sensor accelerometer dan sensor getar.

Uji perbedaan nilai pengukuran dengan menggunakan sensor accelerometer pada smartphone. Selisih perbedaan nilai hasil pengukuran accelerometer yang didapatkan oleh sensor ADXL335 dengan nilai accelerometer pada smartphone pada sumbu $\mathrm{x}$ adalah $0,42 \%$, pada sumbu $\mathrm{y}$ $0,164 \%$ dan pada sumbu $\mathrm{z}$ 0,035\%. Perbedaan ini disebabkan oleh nilai resultan dari rangkaian sensor ADXL335.

\subsection{Desain \\ Menggunakan Arduino DUE \\ Penelitian yang dilakukan oleh Purwowibowo (2017) bertujuan untuk mendesain sistem accelerometer sebagai}


alat pendeteksi getaran pada alat-alat industri untuk mengetahui ada atau tidaknya kerusakan pada mesin-mesin tersebut. Oleh karena itu, dilakukan uji sensor ADXL345 untuk mengetahui seberapa stabil atau konsisten getaran yang dapat dideteksi oleh sensor accelerometer tersebut.

Kesimpulannya, kinerja ADXL345 sangat bergantung pada kondisi pengukuran yaitu frekuensi dan nominal akselerasi yang diukur. Kemampuan pengukuran ADXL345 paling optimal pada frekuensi $31,5 \mathrm{~Hz}$ dan $40 \mathrm{~Hz}$ dengan nominal akselerasi $1 \mathrm{~g}$ dan 1,5 g. Pada titik tersebut, ketidakpastian mencapai 1,6\%.

\section{TEORI DASAR}

\subsection{Gelombang Seismik}

Gelombang seismik diartikan sebagai suatu gelombang yang merambat di permukaan dan di dalam bumi. Gelombang yang merambat di permukaan bumi disebut surface wafe dan yang merambat melalui interior bumi disebut body wave (Aster, 2011).

\subsubsection{Gelombang badan (body wave)}

Gelombang badan adalah gelombang yang menjalar di dalam bumi sebagai media elastik dan arah perambatannya keseluruh bagian di dalam bumi. Berdasarkan sifat pergerakan partikel dan arah penjalarannya, gelombang dapat dibedakan menjadi gelombang $\mathrm{P}$ dan $\mathrm{S}$.

Gelombang $\mathrm{P}$ disebut juga sebagai gelombang kompresi.gelombang longitudinal. Gelombang P memiliki cepat rambat paling tinggi dan dapat merambat pada medium cair maupun padat (Aster, 2011).

Sedangkan gelombang $\mathrm{S}$ disebut gelombang geser atau shear atau transversal. Kecepatan rambat gelombang ini lebih lambat dibandingkan gelombang $\mathrm{P}$ dan hanya dapat merambat pada medium padat. Gelombang $\mathrm{S}$ bergerak tegak lurus terhadap arah rambat. Perambatan gelombang $\mathrm{S}$ disertai dengan gerakan partikel yang berputar sehingga lebih berbahaya dibanding gelombang $\mathrm{P}$ karena dapat menyebabkan pergeseran (Aster,2011).

\subsubsection{Gelombang Permukaan}

Gelombang permukaan merupakan gelombang seismik yang merambat di permukaan maupun pada batas permukaan medium. Gelombang permukaan memiliki frekuensi rendah dan amplitudo yang besar karena penjalaran diakibatkan oleh efek free surface, dimana terdapat perbedaan sifat elastik yang besar. Gelombang permukaan terdiri dari gelombang rayleigh dan gelombang love.

Gelombang rayleigh memiliki orbit gerakan elips yang bergerak tegak lurus dengan permukaan dan arah penjalarannya. Gelombang ini terjadi akibat interferensi antara gelombang tekan (pressure) dengan gelombang geser (shear) secara konstruktif. Gelombang love merambat di permukaan dalam bentuk gelombang transversal dan merupakan hasil dari gelombang $\mathrm{S}$ horizontal yang penjalarannya paralel dengan permukaannya (McGuire, 2004).

\subsection{Mikrotremor}

Tremor dapat diartikan sebagai suatu getaran yang terus menerus terjadi dikarenakan berbagai sumber getaran. Mikrotremor sendiri dikenal sebagai suatu vibrasi tanah dengan amplitude displacement sekitar 0,1-1 mikron dengan amplitude velocity $0,001-0,01 \quad \mathrm{~cm} / \mathrm{s}$ (Mirzaoglu dan Dykmen, 2003). Getaran ini dapat disebabkan oleh gangguan buatan seperti aktivitas lalu lintas, mesin pabrik, dan sebagainya.

Mikrotremor terjadi secara terus menerus, terjadi saat getaran harmonik alami tanah yang terjebak dilapisan sedimen permukaan, terpantulkan oleh adanya bidang batas lapisan dengan frekuensi yang tetap, disebabkan oleh getaran mikro di bawah permukaaan tanah dan kegiatan alam lainnya. Penelitian mikrotremor dapat digunakan untuk 
mengetahui karakteristik lapisan tanah berdasarkan parameter frekuensi dominannya dan faktor penguatan gelombangnya (Mirzaoglu dan Dykmen, 2003).

\subsection{Frekuensi Dominan}

Frekuensi dominan adalah frekuensi yang muncul sebagai nilai frekuensi dari lapisan batuan di suatu wilayah yang menunjukkan karakteristik serta jenis batuan yang ada di bawah permukaan tanah (Sungkono, 2011). Hal ini dapat diketahui berdasarkan klasifikasi tanah dan nilai frekuensi dominan tanah yang diklasifikasikan oleh Kanai (1983) pada Tabel 1.

Nilai frekuensi dominan (fo) yang dimiliki struktur bangunan seperti jembatan tidak boleh memiliki kesamaan dengan nilai frekuensi dominan $(f O)$ yang dimiliki oleh gangguan vibrasi yang salah satunya aktifitas manusia karena akan mengalami resonansi jika $f O$ dari kendaraan menyamai $f 0$ jembatan. Nilai periode dominan didapatkan berdasarkan perhitungan berikut ini (Arifin, dkk., 2013).

$$
\begin{aligned}
& T_{0}=\frac{1}{f_{0}} \ldots \ldots \ldots \ldots \ldots \ldots \ldots \ldots \ldots \ldots \ldots \ldots \ldots \ldots \ldots \\
& T_{0}=\text { Periode Dominan }(\mathrm{s}) \\
& f_{0}=\text { frekuensi dominan }(\mathrm{Hz})
\end{aligned}
$$

\subsection{Metode HVSR}

Teknik HVSR (Horizontal to Vertical Spectral Rasio) pada analisis mikrotremor telah digunakan secara luas untuk studi efek lokal dan mikrozonasi. Selain sederhana dan bisa dilakukan kapan dan dimana saja, teknik ini juga mampu mengestimasi frekuensi resonansi secara langsung tanpa harus mengetahui struktur kecepatan gelombang geser dan kondisi geologi bawah permukaan lebih dulu. Menurut Nakamura (1989) bahwa metode HVSR dalam analisis mikrotremor bisa digunakan untuk memperoleh frekuensi natural sedimen (Aini, dkk., 2012).

Adapun persamaan HVSR dinyatakan sebagai berikut (Nakamura, 2008):
$S_{m}(w)=\frac{\sqrt{\left(H_{S N}(w)\right)^{2}+\left(H_{W E}(w)\right)^{2}}}{V_{S}(w)} \ldots(2)$

$S_{m}(w)=H V S R$ (Horizontal to Vertical Seismic Ratio)

$H_{S N}(w)=$ Nilai amplitudo spectrum frekuensi komponen Utara-Selatan

$H_{W E}(w)=$ Nilai amplitudo spectrum frekuensi komponen Barat -Timur

$V_{s}(w)=$ Nilai Amplitude spektrum frekuensi komponen vertikal

\section{METODELOGI PENELITIAN}

\subsection{Alat dan Bahan}

Alat dan bahan yang digunakan dalam penelitian ini adalah sebagai berikut:

1. Laptop

2. Arduino Mega2560

3. Sensor ADXL345 RTC Module, SD Card Module dan 20x4 LCD

4. Kabel, Saklar, box listrik dan bubble waterpass

5. Software Arduino IDE

\subsection{Prosedur Penelitian}

\subsubsection{Perancangan Elektronik}

Perancangan perangkat elektronik terdiri dari rangkaian komponen berupa sensor ADXL345, microcontroller Arduino, RTC, Data Logger, LCD Display dan sistem power.

Proses rancang bangun dimulai dari menyatukan semua konfigurasi pin sesuai tabel kemudian menyusun rencana peletakan masing-masing komponen dalam suatu wadah berukuran $25 \mathrm{~cm} \times 12 \mathrm{~cm} \mathrm{x}$ $5 \mathrm{~cm}$. Untuk perencanaannya, tubuh alat sebagai wadah komponen terbuat dari mika plastik yang cukup untuk dapat menahan getaran dan desain bagian bawah menggunakan plat besi agar dapat merambatkan getaran dan tidak meredam getaran.

\subsubsection{Perancangan Sistem Program}

Pada perancangan sistem program seperti Gambar 3 ini, alat yang dibuat ber- 
tujuan untuk merespons terhadap getaran horizontal $(\mathrm{E}-\mathrm{W}),(\mathrm{N}-\mathrm{S})$ dan vertikal $(\mathrm{Z})$ yang dibaca melalui ADXL345 berdasarkan domain waktu bersamaan dengan bekerjanya komponen $R T C$ sebagai pemberi informasi waktu (clock) dan kemudian hasil pembacaan langsung disimpan kedalam SD Card melalui modul $S D$ Card dan ditampilkan ke $L C D$ dengan modul $L C D$.

\subsection{Pengujian (Validasi)}

Pengujian ini dilakukan untuk yang dilakukan dilakukan ketika alat dan sistem telah selesai dibuat. Adapun tahap pengujian yang dilakukan yaitu validasi dengan metode $H V S R$.

Pengolahan ini bertujuan untuk mendapatkan rasio spectrum horizontal to vertical $(H / V)$. Data mentah yang diperoleh dari pengukuran lapangan berupa tiga komponen sinyal dalam fungsi waktu. Kemudian sinyal tersebut dilakukan filtering untuk memilih range frekuensi. Setelah itu dilakukan transformasi fourier (FFT) komponen sinyal (SESAME, 2004)

\section{HASIL DAN PEMBAHASAN}

\subsection{Perancangan Elektronik}

Perancangan sistem elektronik bertujuan untuk menentukan proses urutan sistem yang bekerja seluruhnya dengan proses kerja yang efisien dan optimal. Pengujian telah dilakukan untuk mengetahui kecepatan yang dibutuhkan untuk memproses seluruh modul secara bersamaan dengan beberapa sambungan serial maupun paralel dan kemudian menghasilkan sambungan yang dapat berjalan dengan baik jika beberapa modul tidak disambungkan secara seri dengan modul yang lain untuk mempercepat proses akuisisi data penyimpanan data dan display data.

Pada Gambar 4, rancang bangun bentuk tubuh alat bebentuk box dengan ukuran 18,5 cm x $12 \mathrm{~cm} \times 7 \mathrm{~cm}$. Bagian alas box terbuat dari bahan plat besi yang dapat merambatkan getaran dengan baik dan tutup box terbuat dari mika yang ringan sehingga mudah dibawa. Untuk kaki sebagai leveling, terbuat dari alumunium berjumlah 3 dengan jarak leveling dari permukaan $3 \mathrm{~cm}-5 \mathrm{~cm}$. Bagian atas tutup terdapat layar $L C D$ utuk menampilkan status alat saat pengukuran, tombol on-off, tombol light LCD, lubang sebagai penglihatan leveling waterpass di dalam alat. Bagian samping box terdapat push button.

\subsection{Perancangan Sistem Program}

Perancangan urutan kerja dimulai dari menghidupkan power dan pastikan sumber tenaga masih stabil dan dapat digunakan selama akuisisi. Kemudian melakukan inisialisasi seluruh perangkat apakah tersambung atau belum tersambung yang kemudian statusnya ditampilkan ke layar LCD. Jika sudah siap maka akan menampilkan status siap untuk pengukuran.

Untuk mulai melakukan pengukuran, tekan tombol hingga status berubah ditampilkan pada layar $L C D$ dengan status sedang melakukan akuisisi. Seluruh program yang dijalankan, dibuat dengan menggunakan pemrograman pada software Arduino IDE. Selain itu, data yang disimpan dalam format biner hanya dapat dilakukan konversi dengan mesin Arduino yang telah diprogram dengan program yang sama pada saat penyimpanan dengan format biner. Dari pengujian yang telah dilakukan, sampling rate 500/s dapat dilakukan dengan normal hingga selesai pengukuran.

Untuk akuisisi selama 30 menit umumnya memerlukan 20 menit waktu untuk konversi. Dalam melakukan pengujian, dalam proses konversi, dapat mengalami kegagalan atau berhenti bekerja. Jika terjadi maka perlu dilakukan konversi ulang dari data biner tersebut.

Untuk pengaturan parameter data rate, pengaturan dilakukan melalui script Arduino IDE. Untuk pengujian, data rate yang digunakan 0,002 s. Data yang telah dikonversi memiliki format *.csv dengan format header waktu mulai, ti (durasi 
pengukran dalam microsecond dimulai dari 0), ax (data sumbu x), ay (data sumbu y) dan az (data sumbu z) dengan delimiter comma.

\subsection{Validasi Hasil Pengukuran \\ 5.3.1 Titik 1}

Hasil dari pengukuran titik 1 dari alat uji coba menghasilkan nilai $f O=0,211477$ $\mathrm{Hz}$ dan nilai dari alat Reftek menghasilkan $f O=0,204226 \mathrm{~Hz}$. Kurva HVSR memiliki selisih sebesar 0,007251 Hz. Dengan filter window yang digunakan sebesar 50s dengan banyak window 30 .

\subsubsection{Titik 2}

Kurva dari alat uji coba menghasilkan nilai $f O=0,206845 \mathrm{~Hz}$ dan dari alat Reftek menghasilkan nilai $f O=0,182166 \mathrm{~Hz}$. Selisih antara kedua nilai $H V S R$ sebesar 0,024679 Hz. Gelombang yang dilakukan pengambilan sebagai data tremor memiliki lebar window 55s sebanyak 26 window.

\subsubsection{Titik 3}

Dari kurva HVSR yang telah dihasilkan, dari alat uji menghasilkan nilai $f O=0,331194 \mathrm{~Hz}$ dan dari alat Reftek menghasilkan $f O=0,292988 \mathrm{~Hz}$ dengan selisih sebesar 0,12996 Hz. Ukuran window yang digunakan sebesar 47 s dengan banyak window 33 .

\subsubsection{Titik 4}

Dari analisis kurva HVSR alat uji, menghasilkan nilai $f O=0,9377 \mathrm{~Hz}$ dan dari alat Reftek menghasilkan nilai fo = $0,907173 \mathrm{~Hz}$. Selisih nilai antara kedua nilai tersebut adalah $0,026527 \mathrm{~Hz}$. Lebar window yang dipilih yaitu 30s dengan banyak window 40 dengan dipilih waktu window yang sama diantara kedua data.

\subsubsection{Titik 5}

Dari analisis kurva HVSR alat uji menghasilkan nilai $f O=0,24771 \mathrm{~Hz}$ dan dari kurva HVSR Reftek menghasilkan nilai $f O=0,220728 \mathrm{~Hz}$. Selisih antara kedua kurva tersebut sebesar 0,026982 Hz. Lebar window yang dipilih adalah sebesar $49 \mathrm{~s}$ dengan banyak window 24 dengan pick tremor di waktu yang sama antara kedua alat

\subsubsection{Titik 6}

Dari pengukuran titik 6 menghasilkan nilai $f O$ dari kurva $H V S R$ dari alat uji sebesar $f O=0,193777 \mathrm{~Hz}$ dan Reftek sebesar $f O=$ $0,204774 \mathrm{~Hz}$. Dengan selisih nilai fo sebesar 0,010997 Hz. Ukuran window yang dgunakan sebesar $57 \mathrm{~s}$ dengan window sebanyak 19.

\subsection{Analisis Hasil Validasi}

Dari seluruh nilai $f O$ yang telah dilakukan analisis, selisih terkecil antara kedua alat pengukuran yaitu $0,00725 \mathrm{~Hz}$ di titik 1 dan selisih terbesar yaitu $0,129 \mathrm{~Hz}$ di titik 3. Rata rata selisih antara kedua nilai $f 0$ pengukuran yaitu $0,037 \mathrm{~Hz}$.

Untuk membuktikan tingkat kepercayaan kurva HVSR yang telah dianalisis, dilakukan pengujian curve realibility dengan syarat kurva pada Tabel 2.

Dari syarat yang dibutuhkan, berdasarkan kriteria curve reliability, maka nilai fo hasil pengukuran dan proses data lulus terhadap syarat dari kurva $H V S R$ yang ditunjukkan oleh nilai hasil kalkulasi pada Tabel 3 dan semua nilai $f 0$ yang dihasilkan memiliki kategori jenis tanah yang sama dari alat uji maupun reftek accelerograph di dalam kategori IV menurut klasifikasi Kanai (1983).

\section{KESIMPULAN DAN SARAN}

\subsection{Kesimpulan}

Kesimpulan yang didapat dari hasil penelitian ini adalah sebagai berikut:

1. Hasil rancang bangun bentuk tubuh alat berbentuk box dengan ukuran 18,5 cm x $12 \mathrm{~cm} \times 7 \mathrm{~cm}$. Bagian alas box terbuat dari bahan plat besi yang dapat merambatkan getaran dengan baik dan tutup box terbuat dari mika. Dengan ukuran box tersebut, komponen dapat disusun secara efisien dan dapat bekerja 
dengan optimal berdasarkan uji pengukuran.

2. Rancang sistem elektronik dan pemrograman accelerometer berbasis Arduino berhasil dilakukan dimulai dari pemasangan seluruh modul elektronik, membuat program yang dapat bekerja dengan efisien dari segi kecepatan dan energi yang dibutuhkan saat bekerja dengan sampling rate pengambilan data maksimal 500/s.

3. Dari hasil uji validasi, dihasilkan nilai $f 0$ dari kurva $H V S R$ dari masing-masing titik dari alat uji berkisar antara $0,193 \mathrm{~Hz}$ - 0,933 Hz. Sedangkan dari alat Reftek Accelerograph menghasilkan nilai kisaran 0,182 Hz - 0,907 Hz. Selisih terkecil antara kedua alat pengukuran yaitu $0,00725 \mathrm{~Hz}$ di titik 1 dan selisih terbesar yaitu $0,129 \mathrm{~Hz}$ di titik 3. Rata rata selisih antara kedua nilai $f 0$ pengukuran yaitu $0,037 \mathrm{~Hz}$.

\section{DAFTAR PUSTAKA}

ADXL345 Overview, 2019, https://www.analog.com/en/products/a dx1345.html, Diakses pada 14 Januari 2019 pukul 14:53 WIB.

Aini, D., Utama, W. dan Bahri, A., 2012, Penaksiran Resonansi Tanah dan Bangunan Menggunakan Analisis Mikrotremor Wilayah Surabaya Jawa Timur. Jurnal Teknik POMITS, pp. 1-5.

Aqeel, A., Introduction to Arduino Mega 2560, 2019, https://www.theengineerin gprojects.com/2018/06/introduction-toarduino-mega -2560.html, Diakses pada 14 Januari 2019 pukul 15.30 WIB.

Arduino, 2019, Introduction to Arduino Mega 2560 Rev 3, https://store .arduino.cc/usa/arduino-mega-2560rev3, Diakses pada 14 Januari 2019 pukul 15.00 WIB.
Ardhi, C., 2018, Perancangan Alat Pendeteksi Gempa Menggunakan Sensor Accelerometer Dan Sensor Getar. Tugas Akhir :Universitas Telkom: Bandung.

Arifin, S.S., Mulyatno, B.S., Marjiyono, dan Setianegara, R., 2014, Penentuan Zona Rawan Guncangan Bencana Gempabumi Berdasarkan Analisis Nilai Amplifikasi HVSR Mikrotremor dan Analisis Periode Dominan Daerah Liwa dan Sekitarnya, Jurnal Geofisika Eksplorasi Vol. 2/No.1. Universitas Lampung, Lampung.

Aster, R., 2011, The Seismic Wave Equation. Socorro: New Mexico Tech.

Kanai, K., 1983, Engineering Seismology, Tokyo University, Japan.

McGuire, R. K., 2004, Seismic Hazard and Risk Analysis. Earthquake Engineering Research Institute MNO-10.

Mirzaoglu, M. dan Dykmen, U, 2003, Application of Microtremor to Seismic Microzoning Procedure, Journal of The Balkan Geophysical Society, Vol.6 No.3.

Nakamura, Y, 2008, On The $H / V$ Spectrum, The 14th World Conference on Earthquake Engineering October 1217 Beijing, China.

Purwowibowo, 2017, Desain Akselerometer Menggunakan Mikrokontroler Arduino DUE, Instrumentasi Vol. 41 No. 1, Puslit Metrologi LIPI Serpong Tangerang Banten.

SESAME, 2004, Guidelines For The Implementation of The H/V Spectral Ratio Technique on Ambient Vibrations, Europe: SESAME European research project. 
Sungkono, 2011, Evaluation Of building Strength from Microtremor Analysis, International Journal of Civil and Environment Engineering IJCEE-
IJENS Vol:11 No:5, Institut Teknologi Sepuluh Nopember Surabaya

\section{LAMPIRAN}

Tabel 1. Klasifikasi Tanah (Kanai, 1983)

\begin{tabular}{|c|c|c|c|c|}
\hline \multicolumn{2}{|c|}{ Klasifikasi Tanah } & \multirow{2}{*}{$\begin{array}{c}\text { Frekuensi } \\
\text { Dominan }(\mathrm{Hz})\end{array}$} & \multirow{2}{*}{ Klasifikasi Kanai } & \multirow{2}{*}{ Deskripsi } \\
\hline Tipe & Jenis & & & \\
\hline \multirow{2}{*}{ Tipe IV } & Jenis I & $6,7-20$ & $\begin{array}{l}\text { Batuan terser atau } \\
\text { lebih tua. Terdiri } \\
\text { dari batuan Hardy } \\
\text { Sandy, gravel, dll }\end{array}$ & $\begin{array}{l}\text { Ketebalan sedimen } \\
\text { permukaannya sangat } \\
\text { tipis, didominasi oleh } \\
\text { batuan keras }\end{array}$ \\
\hline & Jenis II & $4-6,7$ & $\begin{array}{l}\text { Batuan alluvial, } \\
\text { dengan ketebalan } \\
5 \mathrm{~m} \text {. Terdiri dari } \\
\text { sandy-gravel, } \\
\text { sandy hard clay, } \\
\text { loam, dll }\end{array}$ & $\begin{array}{c}\text { Ketebalan sedimen } \\
\text { permukaannya masuk } \\
\text { dalam kategori menengah } \\
5-10 \mathrm{~m}\end{array}$ \\
\hline Tipe III & Jenis III & $2,5-4$ & $\begin{array}{l}\text { Batuan alluvial, } \\
\text { dengan ketebalan } \\
>5 \mathrm{~m} \text {. Terdiri dari } \\
\text { sandy-gravel, } \\
\text { sandy hard clay, } \\
\text { loam, dll }\end{array}$ & $\begin{array}{c}\text { Kategori sedimen } \\
\text { permukaan masuk dalam } \\
\text { kategori tebal, sekitar } 10 \\
-30 \mathrm{~m}\end{array}$ \\
\hline Tipe II & & & $\begin{array}{c}\text { Batuan alluvial } \\
\text { yang terbentuk } \\
\text { dari sedimentasi }\end{array}$ & Ketebalan sedimen \\
\hline Tipe I & Jotis & , & $\begin{array}{l}\text { lumpur, dll. } \\
\text { Dengan kedalaman } \\
30 \mathrm{~m} \text { atau lebih }\end{array}$ & tebal \\
\hline
\end{tabular}

Tabel 2. Syarat Curve Reliability HVSR (SESAME, 2004)

\begin{tabular}{|c|c|}
\hline i) & $f 0>10 / l w$ \\
\hline ii) & $n c(f 0)>200$ \\
\hline \hline \multicolumn{2}{|c|}{$l w=$ window length } \\
$n w=$ number of windows \\
$n c=l w . n w . f 0$ \\
$f 0=$ peak frequency \\
\hline
\end{tabular}


Tabel 3. Nilai $f O$ (a) Alat Uji dan (b) Reftek untuk nilai curve reliability

\begin{tabular}{|c|c|c|c|c|c|c|c|}
\hline Titik & $f O(\mathrm{a})$ & $f O(\mathrm{~b})$ & $\begin{array}{c}\text { Length } \\
\text { Window } \\
(s)\end{array}$ & $\begin{array}{c}\text { Number } \\
\text { of } \\
\text { Window }\end{array}$ & Min. $f 0$ & $N c(a)$ & $N c(b)$ \\
\hline 1 & 0.21 & 0.20 & 50 & 30 & 0.2 & 316.5 & 306 \\
\hline 2 & 0.206 & 0.18 & 55 & 26 & 0.18 & 294.58 & 260.26 \\
\hline 3 & 0.29 & 0.42 & 47 & 33 & 0.21 & 452.89 & 654.52 \\
\hline 4 & 0.93 & 0.90 & 30 & 40 & 0.33 & 1119.6 & 1088.4 \\
\hline 5 & 0.24 & 0.22 & 49 & 24 & 0.20 & 290.47 & 258.72 \\
\hline 6 & 0.19 & 0.20 & 57 & 19 & 0.17 & 209.01 & 220.93 \\
\hline
\end{tabular}

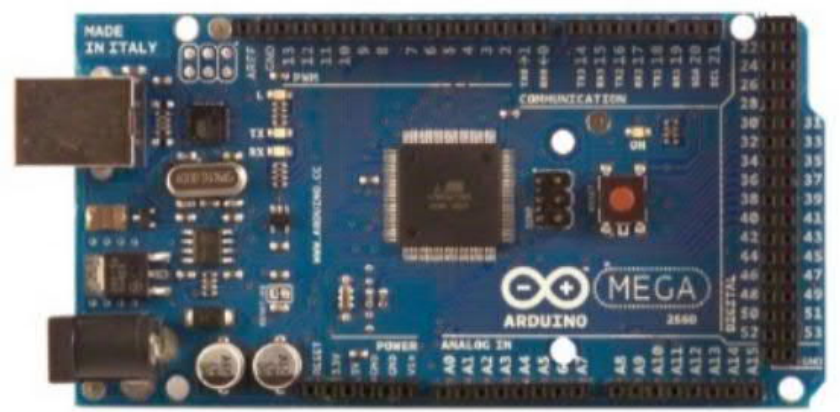

Gambar 1. Arduino Mega2560 (www.arduino.cc)

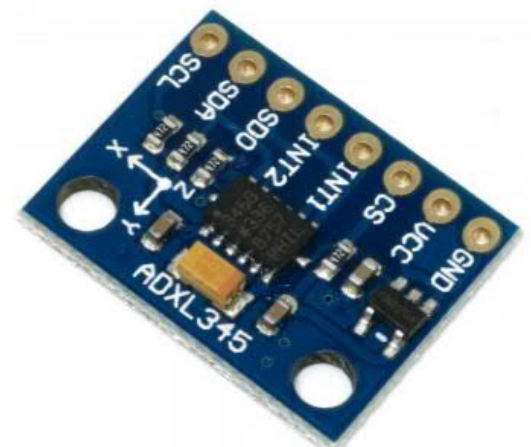

Gambar 2. ADXL345 (www.sparkfun.com) 


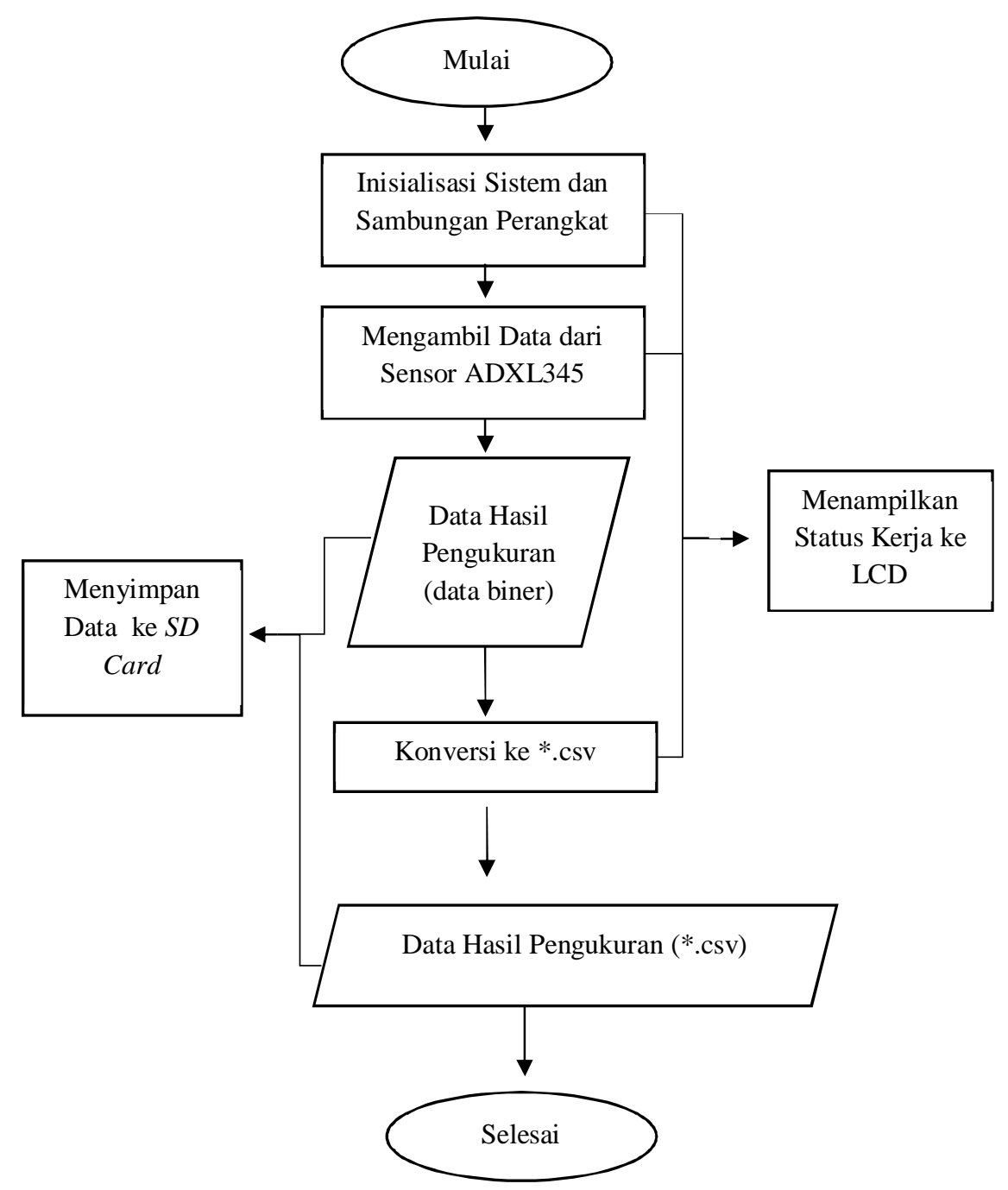

Gambar 3. Flow Chart Penelitian

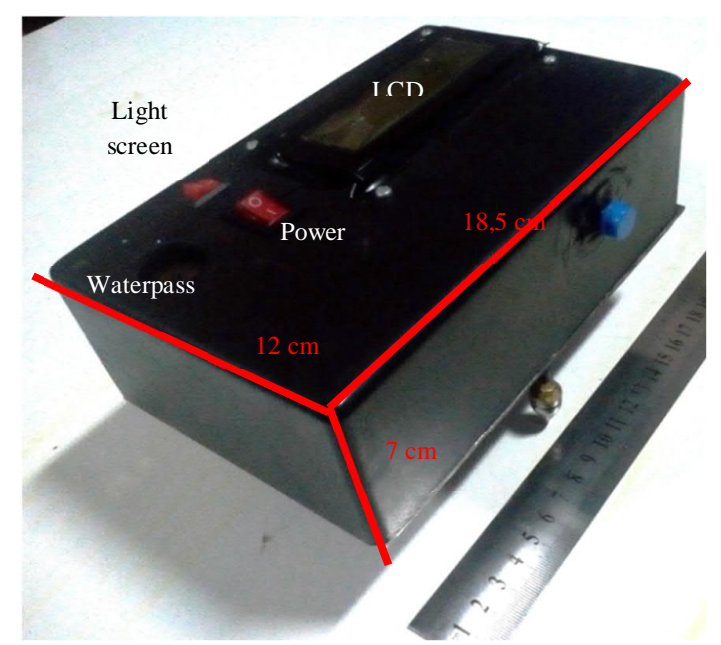

Gambar 4. Hasil Rancang Bangun Tubuh Alat 


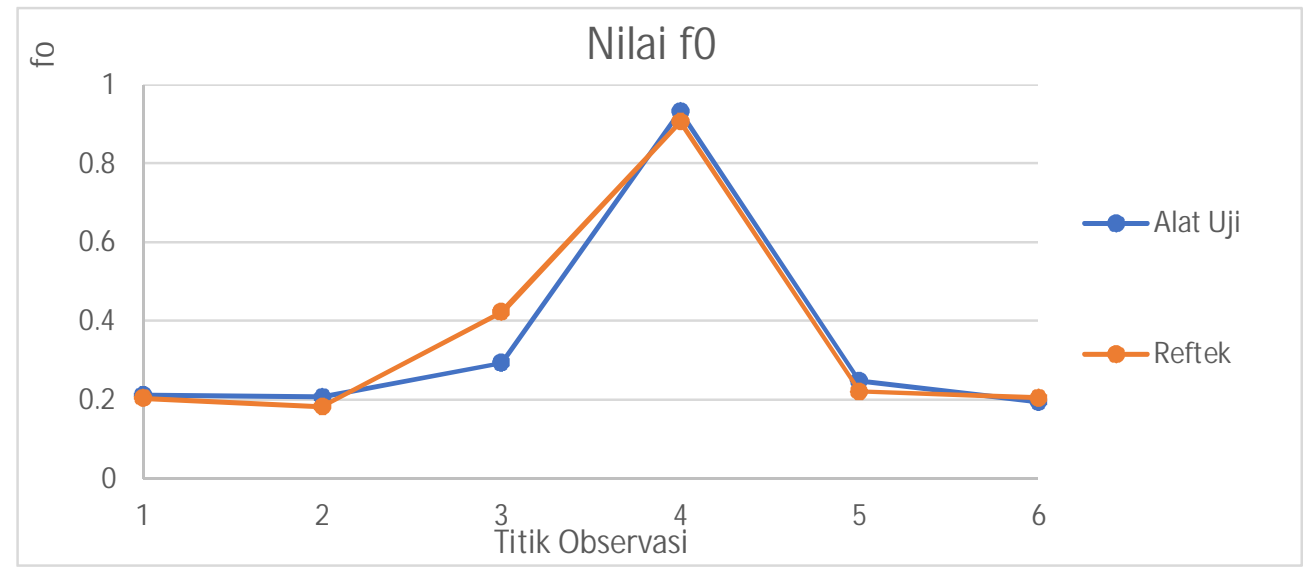

Gambar 5. Titik observasi dan nilai $f O H V S R$ di titik observasi

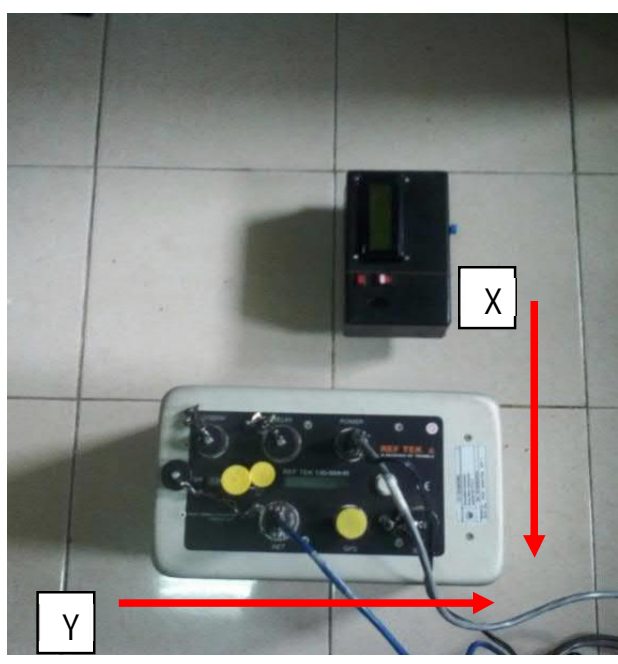

Gambar 6. Lokasi Pengukuran Titik

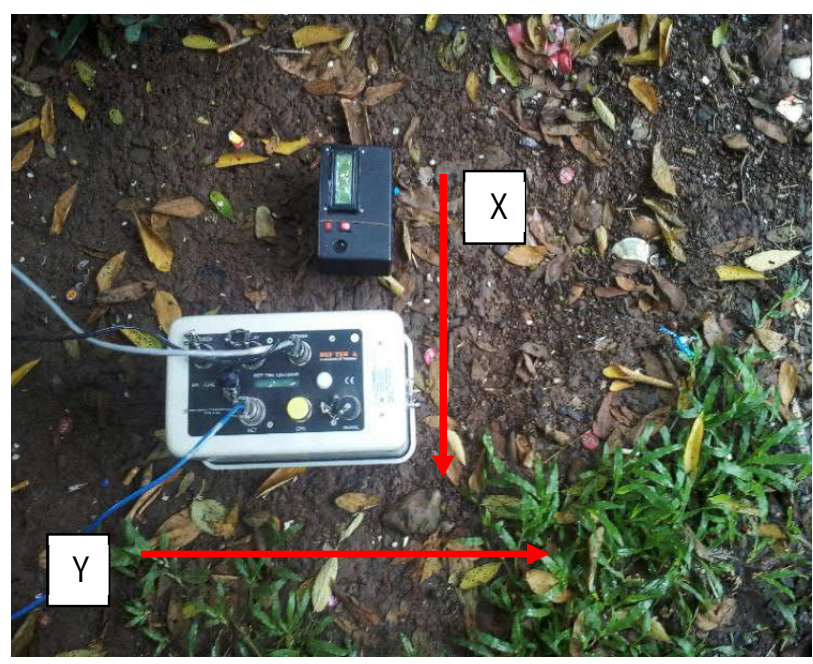

Gambar 7. Lokasi Pengukuran Titik

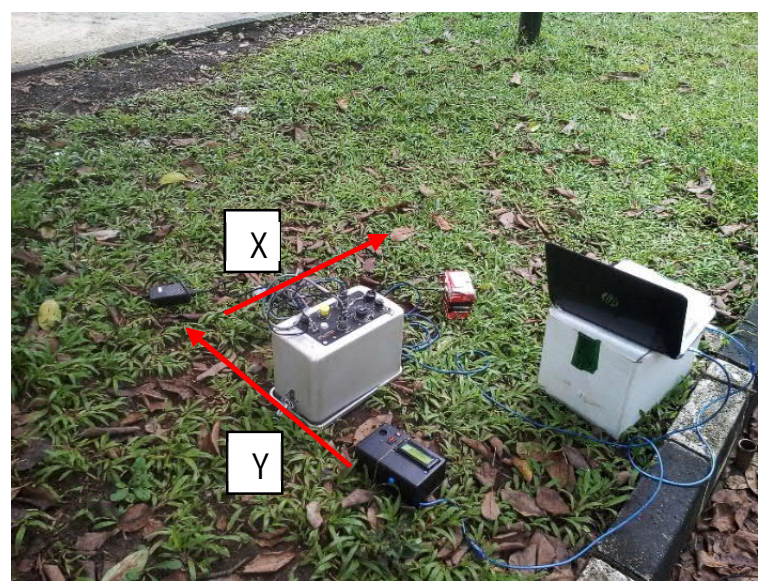

Gambar 8. Lokasi Pengukuran Titik 3

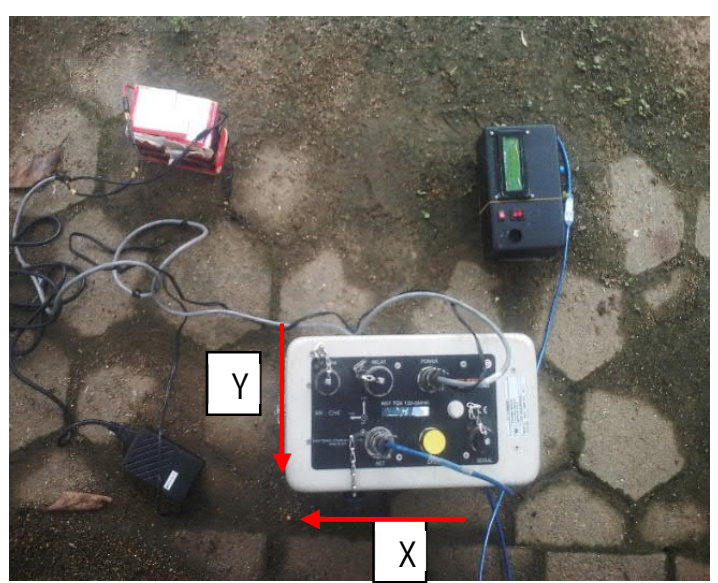

Gambar 9. Lokasi Pengukuran Titik 4 


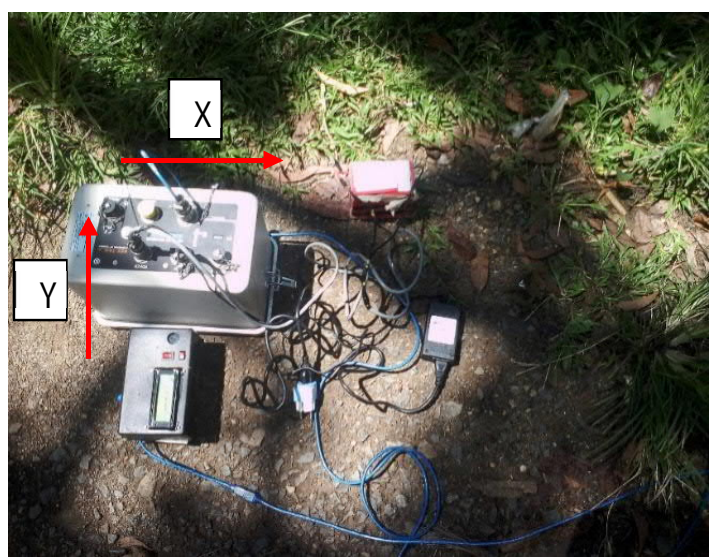

Gambar 10. Lokasi Pengukuran Titik 5

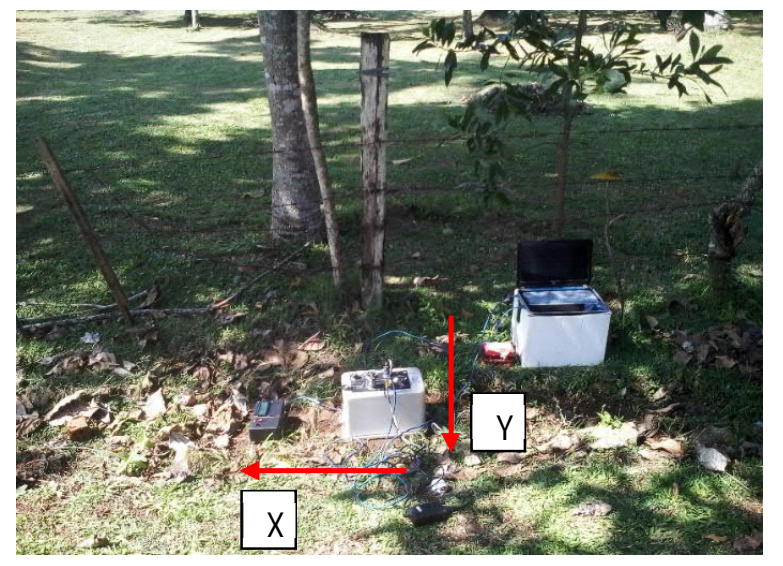

Gambar 11. Lokasi Pengukuran Titik 6

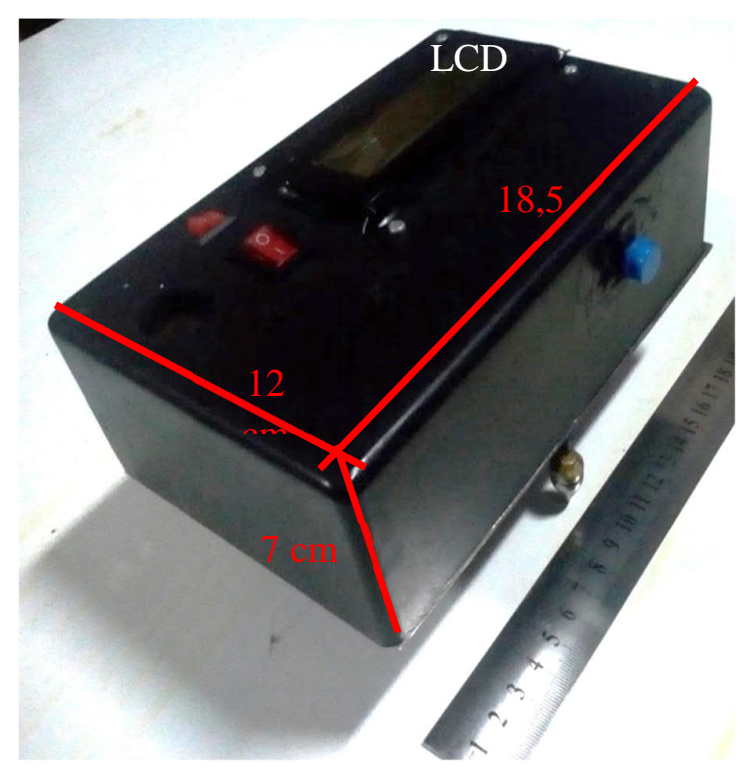

Gambar 12. Hasil Rancang Bangun 1

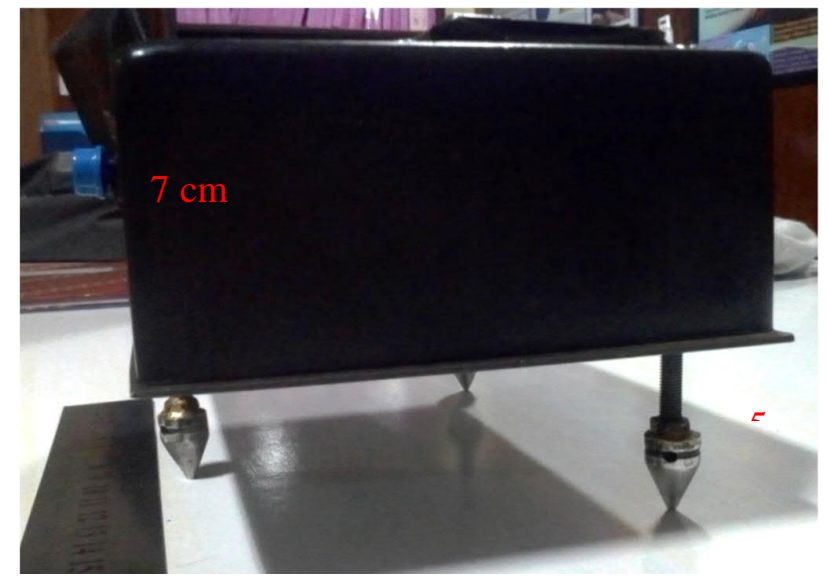

Gambar 13 Hasil Rancang Bangun 2 